\title{
A Comparison Study of Running on Sand and Tartan Track to Increase Cardiovascular Endurance of Universitas Negeri Jakarta Students
}

\author{
Kuswahyudi \\ Faculty of Sport Science \\ Universitas Negeri Jakarta \\ Jakarta, Indonesia \\ kuswahyudi@unj.ac.id
}

\author{
Ramdan Pelana \\ Faculty of Sport Science \\ Universitas Negeri Jakarta \\ Jakarta, Indonesia \\ ramdanpelana@unj.ac.id
}

\begin{abstract}
- the aim of this study is to determine the impact ratio between running on sand and running the tartan track to increase cardiovascular endurance in students of the Sport Science Program at the Universitas Negeri Jakarta. The research was conducted at the Gelanggang Olahraga Rawamangun and the sand volleyball court of the Universitas Negeri Jakarta from January 08 to February 12, 2018. The method used for this research is the experimental method with "Two Group Pre-test and Post-test Design." 20 individuals were selected as samples from the population of 100 people and the purposive sampling technique was applied. The data analysis technique used here is the t-test. Based on the results of the data analysis, $H_{0}$ was rejected and $H_{1}$ accepted, so, a conclusion can be drawn that there is a significant difference between running on sand and running on the tartan track. Exercise run on sand is more influential than exercise run on the tartan track based on improving cardiovascular endurance of the students of Ilmu Keolahragaan Study Program at the Universitas Negeri Jakarta.
\end{abstract}

\section{Keywords-exercise, run, cardiovascular endurance}

\section{INTRODUCTION}

Today, technological advancements make everything a whole lot easier, and this affects the lifestyle of people, especially students. Currently, the fitness levels of a lot of students are below the average physical fitness levels. This occurred because the lack of daily physical activity or exercise.

Sports students are active both in theory and practice, in their daily life; they must follow theoretical lectures and practice much kind of sports. Therefore, they are required to have a good level of physical fitness; one of the attributes includes the component of heart and lung endurance.

Someone with good physical fitness will be able to cope with any workload without incurring any significant fatigue, and even have spare power for emergency use at any time. Hence, a good physical fitness can be obtained by performing regular exercise.

Thus, running is one of the chosen ways to increase the physical fitness level of students. Many people choose running as their exercise because it is cheap, easy, and it can be conveniently done anywhere and anytime. However, most people tend to prefer sports games.

People prefer playing sports games because they think the games are more interesting and a lot more fun, they don't get bored easily so, they sweat more, some of them include volleyball, basketball, futsal, and soccer. Yet, when viewed in terms of benefits for the body, running effectively improves physical fitness, increases heart and lung resistance (cardiovascular). Cardiovascular endurance is the ability of the heart, lungs and blood vessels to function optimally while performing daily activities over a long period of time without experiencing significant fatigue.

Nowadays, many running tracks open to the public such as those created by the government in sports arenas and parks. This can be used to train and improve the level of people's physical fitness, especially students. However, there are other alternatives considered very effective in increasing the level of physical fitness, like running on the sand field. Of course, further investigation is still needed to be conducted.

In this study, will be discuss the benefits of running on tartan track and running on the sand field in increasing cardiovascular endurance. Hopefully, the results obtained in this study can be benefical for sport knowledge, especially for trainers / coaches in choosing effective training methods to improve cardiovascular endurance increase the performance of athletes.

\section{RESULTS AND DISCUSSION}

\section{A. Physical Fitness}

Foremost, throughout life Man cannot be separated from physical activity. It requires conscious and good practice to maintain or improve the quality of physical fitness. However, with regular exercise, we can improve and maintain our physical fitness. Some people carry out the exercise in various forms according to each individual need. Some want to make the body ideal, heal, therapy or maintaining physical fitness.

Bompa in his book "Theory and Methodology of Training" explains that exercise is a systematic activity over a long period of time, progressively enhanced which affects the features of individuals' physiological functions to achieve a defined goal. Based on the theory above, exercise is a concept where a person carries out an activity for a long time, systematically and progressively, so the specific and overall benefits of exercise can be felt. Therefore, it is clear that regular and repetitive exercise improves physical fitness. However, these exercises should be adjusted to the specific conditions of a person (children, adults, elderly and sick). 
More frequent practice can improve some abilities, such as motor ability, physical fitness, physical ability and cardiovascular ability [1].

Cardiovascular endurance is one of the components of physical fitness. A person who has good physical fitness levels will be able to cope with workloads without experiencing significant fatigue and still have spare power for emergency use at any time. Therefore, we can get a good physical fitness by exercising regularly [2].

Physical fitness is a physical condition that describes the potential to perform certain tasks with optimal results devoid of fatigue. Physical freshness is divided into two aspects [3]:

1. Physical fitness-related skills

2. Health-related physical fitness

The components of health-related physical fitness include:

1. Cardiovascular endurance

2. Muscle strength

3. Muscular endurance

4. Flexibility

5. Body composition

Many health experts argue that among the 5 components above, the cardiovascular component is the most important in determining physical fitness. Cardiovascular endurance illustrates how well you are able to utilize oxygen gotten from the atmosphere to the heart, and muscles that work to produce energy. Endurance is very important to support the work of muscles, by taking oxygen and transferring it to the active muscles.

Cardiovascular endurance is the ability of the heart to pump blood to the muscles. It is also the ability of muscles to absorb oxygen from blood or a maximum aerobic capacity. Oxygen is used for the oxidation of carbohydrates and fats to produce energy in the mitochondria.

Cardiovascular endurance is measured in terms of the amount of milliliters of oxygen that can be consumed per $\mathrm{kg}$ body weight in human bodies. Jeanne Wiesseman mentions that there are 5 factors that determine a person's cardiovascular endurance (Vo2 Max) that is:

1. Genetic (heredity)

2. Age

3. Gender

4. Body Composition

5. Exercise

\section{B. Running}

Athletics is often referred to as the "Mother of Sport," consisting of: walks, runs, jumps and throws. These movements are the original and natural human movement. According to Carl Johnson, the easiest and most experienced activity of all sporting activities is running. We all learn to run right after walking, which is why racing is very popular. Running is very easy to do gradually and does not require special equipment.

F.G.E Rorimpandey in his book "Running, Jumping, Throwing" defines running as a way of moving the body along a path by using steps, where after stretching and piling your legs, you enter a flying motion phase where at that period, the legs do not touch the floor [4].

Still, a lot of people cannot tell the difference between walking, running, and jogging. The distinguishing factor between the three of them is the foot impact with the soil. Running has a longer floating phase where both legs are afloat and has a wide and powerful range. The body is slightly forward and landed lower, the arm spans are not so strong, the floating phase is rather short and the full surface of the foot is used to land. To understand the difference between running and jogging better, consider the picture below:

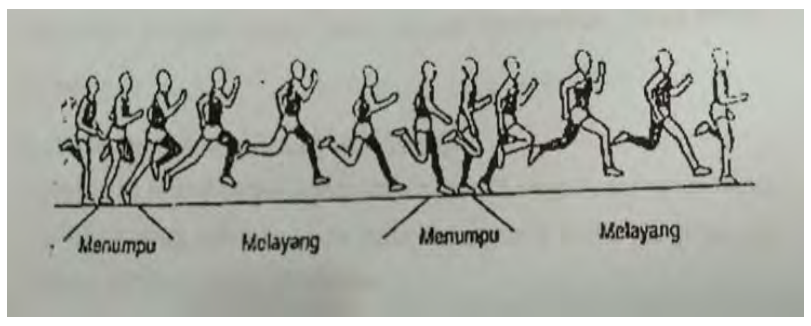

Fig 1. Run and Jogging Motion [5].

\section{Running Track}

Generally, the running track is made of a red brick material. However, the current technological advancements, the running track is now made of tartan tire santel, a kind of synthetic rubber. The foundation of the material is soft but strong and ideal for tracks as it minimizes athlete injury.[6]

The tartan track is a synthetic surface made from polyurethane. The term Track tartan has been known as a synonym for synthetic athletic tracks since the 1968 Olympics in Mexico. Since the tartan brand name is owned by $3 \mathrm{M}$ Company, it became famous worldwide throughout the 1970s;

Here is a tartan track image in accordance with the description above:

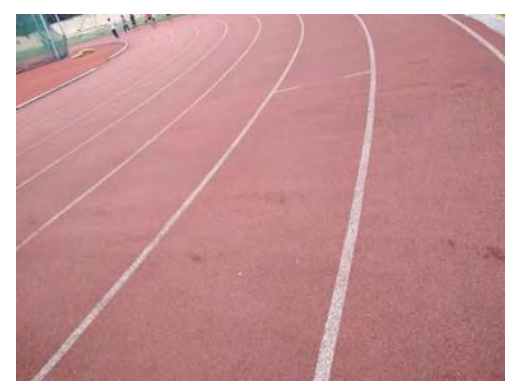

Fig 2. Tartan Track

Tracks like this have become the standard for exclusive competitions. The requirement for this is a field that has several trails with a length of $400 \mathrm{~m}$ and a width of $7.32 \mathrm{~m}$. Made of 6 to 8 trajectories, each with a width of $1.22 \mathrm{~m}$ and a maximum of $1.25 \mathrm{~m}$. On the inside, a limit should be made with cement or any other material with a minimum height of $5 \mathrm{~cm}$ and a minimum width of $5 \mathrm{~cm}$. The shape of the entire track is circular or oval in shape, with the start and finish points already determined by length. The first trajectory measurement is taken from a point $30 \mathrm{~cm}$ out from the inner line in the track, for paths without cemented borders $20 \mathrm{~cm}$ is taken from the inner line of the track. 
Sand can also be efficiently used as a sports tool to burn calories quickly. According to a new study published in the Journal of Strength Conditioning and Resistance, sand can has the ability to burn more calories. The Western Australian Institute of Sport researchers found that our heart beats about 1.1 times faster when performing activities on sand. Due to the uneven sand surface, movement is harder and our bodies struggle to move. In addition, running on sand also stimulates the muscles and the skeletal system. To retrieve the legs embedded in sand, the body needs to move most of the muscles of the body in order to keep running, surely this releases more energy. Sand is an example of a granular material. Sand grains are generally sized between 0.0625 to 2 millimeters. The sand-forming material is silicon dioxide, but in some tropical and subtropical beaches; it is generally formed from limestone. Jogging on sand is very good because the texture of sand is uneven and solid, requiring more energy $[7]$.

Running is a physical activity that almost everyone must have done. Due to the simplicity of this sport, running is a popular option to meet the needs of people's physical activity. Compared to running on the flat tartan tracks that do not need as much energy, running on sand is a relatively more tedious exercise. Foremost, Maximum aerobic speed is used before the program determines the specific distance and running speed during the exercise. However, each individual has different endurance levels. After calculating the maximum aerobic speed, the Tabata exercise program is given. The research studies the comparison between running on sand and the tartan track in order to increase cardiovascular endurance.

\section{THE DATA RESULT}

The data used was obtained from the pretest and post-test of cardiovascular endurance based on observations obtained from the results comparing running on sand and running on the tartan track. The data for the group running on sand can be described as follows [8]:

1. Preliminary test data of the group that ran on sand (X1) result Has the highest Vo2 Max at 51.1 and the lowest Vo2 Max at 36.8, with an average of $(\mathrm{X} 1)=43.71$, standard deviation $(\mathrm{Sx} 1)=4.10$ and standard error mean $(\mathrm{SEmx} 1)=1.36$.

2. Final test data of the group that ran on sand (X2) result Has the highest Vo2 Max at 56.5 and Vo2 Max at 45.5, with average $(\mathrm{X} 2)=50.96$, standard intersection $(\mathrm{S} \times 2)=$ 36.5 and standard error mean $(\mathrm{SEmx} 2)=1.21$.

The research data for this study was obtained from the pre-test and the post-test of cardiovascular endurance based result observation and comparison of running on sand and running on the tartan track. The data for the group running on the tartan track can be described as follows:

1. Initial test data of the group that ran on Track Tartan (Y1) result Has the highest Vo2 Max at 51.1 and the lowest Vo2 Max at 36.8, with average $(\mathrm{Y} 1)=43.44$, standard deviation $(\mathrm{SY} 1)=4.40$ and standard error mean $(\mathrm{SEmY} 1)$ $=1.46$.

2. Final test data for the group that ran on Track Tartan (Y2) with the Highest Vo2 Max at 52.8 and the lowest Vo2 Max at 39.9, with average $(\mathrm{Y} 2)=45.43$, standard deviation $(\mathrm{Y} 2)=4.11$ and standard error mean $(\mathrm{SEmY2})$ $=1.37$.

Based on the results of this research, suggestions that can be given based on the results of this study are as follows:

The results of the pre-test and post-test of cardiovascular endurance of the sand group had an average value of (MD) = 7.25 , standard deviation $(\mathrm{SD})=3.98$, and the standard error mean $(\mathrm{SEMD})=1.32$, the value of $\mathrm{t}$ - count obtained is $=$ 5.492. Then, the result is tested with the t-table at degrees of freedom $(\mathrm{dk})=\mathrm{n}-1=10-1=9$ with the level of trust $(\alpha)=$ 0.05 the critical value t-table obtained is $=2.262$. Thus, the value of $t$-count is greater than $t$-table value $(t$-count $=5.492>$ t-table $=2.262$ )

Based on the data analysis, it can be concluded the null hypothesis (H0) is rejected and the working hypothesis (H1) is accepted, implying that running on sand improves cardiovascular endurance.

The results of the pre-test and post-test of cardiovascular endurance in the Tartan Track group had an average score of $(\mathrm{MD})=1.99$, standard deviation $(\mathrm{SD})=1.22$, and the mean error standard $(\mathrm{SEMD})=0.44$, the value being $\mathrm{t}$-count obtained $=4.975$. Then the result is tested with the t-table on degrees of freedom $(\mathrm{dk})=\mathrm{n}-1=10-1=9$ with the level of trust $(\alpha)=0.05$ obtained the critical value t-table $=4.975$. Thus, the value of the $t$-count is greater than the $t$-table value $(\mathrm{t}$-count $=4.975>\mathrm{t}$-table $=2.262)$.

Based on the data analysis can be concluded the null hypothesis (H0) is rejected and the working hypothesis (H1) is accepted, this implies that running on the tartan track improves cardiovascular endurance.

From the data obtained, the cardiovascular post test run in sand and on the tartan track groups had the value of the standard difference between two mean (SEmxmy) $=1.38$. The value becomes t-count obtained $=3.811$. Then, the result of the calculation is tested with the t-table at degrees of freedom $(\mathrm{dk})=(\mathrm{n} 1+\mathrm{n} 2)-2=(10+10)-2=18$, and the trust level $(\alpha)=0.05$ the obtained critical value t-table 2.101 $\mathrm{t}$-count $=3.811>\mathrm{t}$-table $=2.021)$.

From the data analysis, a conclusion can be drawn that the null hypothesis (H0) is rejected and the working hypothesis (H1) is accepted, hence, it can be concluded that running exercise on sand affects the improves cardiovascular endurance a lot more than on the tartan track.

\section{CONCLUSION AND SUGGESTION}

From this paper, based on the problems raised and supported by theoretical descriptions, research data obtained, and analysis of data conducted, it can be concluded that running exercise in Sand can increase cardiovascular endurance by $7.25 \mathrm{ml} / \mathrm{kg} / \mathrm{min}$ in the students of Universitas Negeri Jakarta, running on Tartan Track can increase cardiovascular endurance by $1.99 \mathrm{ml} / \mathrm{kg} / \mathrm{min}$ in the students of Universitas Negeri Jakarta, and for improving cardiovascular endurance, running on Sand is more effective than running on tartan track which increases by 5.26 $\mathrm{ml} / \mathrm{kg} / \mathrm{min}$ in the students of the sports science study program, Universitas Negeri Jakarta. Based on the results of this study, the authors suggest methods to trainers or teachers, in an attempt to improve cardiovascular endurance in searching for 
samples, attention must be paid to the level of physical fitness. For further research, it is necessary to conduct similar research with more samples. Exercising on sand and on the Tartan Track can considerably increase cardiovascular endurance.

\section{REFERENCES}

[1] T. O. Bompa, "Theory and methodology of training." New York, Human Kinetics, 1999.

[2] D. L. Gallahue, J. C. Ozmun, "Understanding motor development." New York, Mc Graw Hill, 2002

[3] KEMENKES. "Peningkatkan kebugaran jasmani di tempat kerja." Jakarta, Direktorat Bina Kesehatan Kerja dan Olahraga, 2012.

[4] F.G.E. Rorimpandey, "Lari, lompat, lempar." Jakarta, Pembangunan Jakarta, 1980.

[5] IIAF LEVEL I. "Techniques and stages of teaching". PASI Educational Program and Certification Training System, 1994.

[6] Y. Adisasmita, "Olahraga pilihan atletik." Jakarta, DEPDIKBUD, 1992.

[7] P. Zamparo, "The energy cost of walking or running on sand", Europan Journal of Applied Physiology, 1992, vol. 65, p183-187.

[8] A. Sudijono. "Pengantar statistik pendidikan." Yogyakarta, Andi, 2000. 